\title{
Distribution and career choices of Canadian trainees in gastroenterology
}

\author{
PAUl C ADAMS MD, IAIN MURRAY MD, GORDON BIERBRIER MD
}

PC ADAMS, I MURRAY, G BIERBRIER. Distribution and career choices of Can- adian trainees in gastroenterology. Can J Gastroenterol 1995;9(2):101-103.

OBJECTIVES: To study the career choices, academic productivity and geographical distribution of trainees in gastroenterology from Canadian training programs from 1984-91.

METHODS: The names and current locations of trainees in gastroenterology were requested from program directors. Data were obtained from CD-ROM on the publications of the trainees during their fellowship. Migration patterns and trends were analyzed over the study period.

RESULTS: Data were obtained on 170 trainees. Forty-one per cent of trainees were working in a hospital affiliated with a university medical centre. Most Canadian trainees continue to practise gastroenterology in the province in which they trained. Trainees who pursued an academic career had an average of 1.1 peerreviewed publication compared with community-based gastroenterologists who averaged 0.40 publications during their fellowship $(\mathrm{P}=0.02)$.

CONCLUSIONS: Many Canadian gastroenterology trainees continue to be affiliated with an academic medical centre. Those trainees who published during their fellowship were associated with a career at an academic centre. Migration to other provinces or countries is uncommon and did not significantly change over the study period.

Key Words: Academic medicine, Education, Residents

\section{Distribution et choix de carrière des stagiaires canadiens en gastro-entérologie}

OBJECTIFS : Étudier les choix de carrière, le rendement scolaire et la distribution géographique des stagiaires en gastro-entérologie inscrits à des programmes de formation au Canada entre 1984 et 1991.

MÉTHODES : Les auteurs se sont adressés aux directeurs des programmes pour se procurer les noms des stagiaires en gastro-entérologie et leurs lieux de formation. Les données ont été obtenues à partir de CD-ROM des publications des stagiaires au cours de leurs stages de formation. Les modes de déplacement et les tendances ont été analysés au cours de la période de l'étude.

RÉSULTATS : Des données ont été obtenues sur 170 stagiaires. Quarante et un pour cent des stagiaires travaillaient dans un hôpital affilié à un centre hospitalier

voir page suivante

Department of Gastroenterology, University of Western Ontario, London, Ontario

Correspondence: Dr Paul C Adams, Department of Gastroenterology, University Hospital, PO Box 5339, London, Ontario N6A 5A5. Telephone (519) 663-3513, Fax (519) 663-3232, email padams@julian.uwo.ca

Received for publication July 28, 1994. Accepted October 11, 1994
$\mathrm{G}$ ASTROENTEROLOGY HAS BECOME one of the most popular career choices among trainees in internal medicine. The expanding role of diagnostic and therapeutic endoscopic procedures has contributed to this rapid growth. Specialist training in gastroenterology is available at 12 medical centres. A long term follow-up of trainees has not been done; to assess this complex issue further we studied the distribution and career choices of trainees from Canadian gastroenterology training programs from 1984-91.

\section{TRAINEES AND METHODS}

Program directors in gastroenterology were requested by mail to provide a list of trainees in gastroenterology since 1984 and their current addresses. Addresses were confirmed using the 1993 Canadian Medical Directory and American Directory of Medical Specialists. Trainees were considered to work at an academic medical centre if they were listed as working at a hospital affiliated with a university medical centre. The size of the city of practice was determined from Canadian census data. Trainees practising in a direct suburb of a major city (eg, Mississauga, Ontario or Richmond, British Columbia) were considered to be working in the major city nearby for the purpose of this study.

As an indirect measurement of academic productivity during their fellowship, a CD-ROM MEDLINE search of publications was performed for all trainees; this search looked for articles 
universitaire. La plupart des stagiaires canadiens continuent leur pratique en gastro-entérologie dans la province où ils ont été formés. Les stagiaires qui poursuivaient une carrière universitaire avaient en moyenne publié 1,1 article dans une revue révisée par des pairs, contre 0,40 publication pour les gastroentérologues en pratique communautaire, au cours de leur stage $(\mathrm{P}=0,02)$.

CONCLUSIONS : De nombreux stagiaires canadiens en gastro-entérologie continuent d'être affiliés à un centre hospitalier universitaire. Les stagiaires, qui ont publié au cours de leur stage de formation, ont eu tendance à poursuivre leur carrière dans un centre universitaire. La migration vers d'autres provinces ou vers d'autres pays est rare et n'a pas changé de façon significative au cours de la période d'étude.

from one year into their fellowship until two years following fellowship completion. Trainees who completed further research training may have published beyond the three-year 'window' used in this study. Similarly, some trainees had publications before their fellowship included in this fellowship period. Publications were verified by identification of faculty from the training centre and were categorized from the abstract as a scientific report, case report or review article. Letters to the editor, book chapters, abstracts and publications that are not listed in Index Medicus were not included in the analysis. Participating centres were not identified by name by agreement with the program directors because of the sensitivity of the subject matter and the potential for errors.

\section{RESULTS}

Data were available from all 12 centres with gastroenterology training programs: University of British Columbia, University of Alberta, University of Calgary, University of Western On- tario, University of Toronto, McMaster University, Queen's University, University of Ottawa, McGill University, University of Montreal, University of Sherbrooke and Dalhousie University. A list of 170 trainees was used for the further analysis.

The percentage of trainees who have chosen careers affiliated with an academic centre is shown by centre in Figure 1 . Of all the trainees, $41 \%$ are working at a university-affiliated hospital. The percentage of trainees entering an academic career is illustrated according to their initial fellowship year in Figure 2. Of the trainees who underwent fellowship training in Ontario $(n=80), 36 \%$ have relocated to another province. Of the trainees who underwent training outside Ontario $(n=84)$, $11 \%$ have migrated to Ontario. The locations of trainees who relocated outside Canada are shown in Table 1 . The mean and median population of the city of practice was approximately 621,000 and 307,000 , respectively (range 5188 to $2,200,000$ ). Ten per cent of the sample were listed in a city
TABLE 1

Geographic relocations of gastroenterology trainees who relocated outside Canada

\begin{tabular}{lc}
\hline United States & Number \\
\hline California & 5 \\
Ohio & 3 \\
Texas & 2 \\
New York & 1 \\
Wisconsin & 1 \\
lowa & 1 \\
Massachusetts & 1 \\
Minnesota & 1 \\
Florida & 1 \\
Vermont & 1 \\
Other countries & \\
Saudi Arabia & 3 \\
Ethiopia & 2 \\
France & 2 \\
Kuwait & 1 \\
Thailand & 1 \\
Mexico & 1 \\
Italy & 1 \\
Honduras & 1 \\
\hline
\end{tabular}

of less than 20,000 and $22 \%$ in a city of greater than one million.

The computer search for publications over the fellowship period uncovered 139 publications. Eighty-four per cent of these publications were in international journals. Of the publications, $67 \%$ were classified as scientific reports, $21 \%$ as case reports and $12 \%$ as review articles. Trainees who pursued an academic career had an average of $1.1 \pm 0.11$ publications during their fellowship compared with community gastroenterologists who averaged $0.40 \pm 0.09$ publications (mean $\pm \mathrm{SE}$,

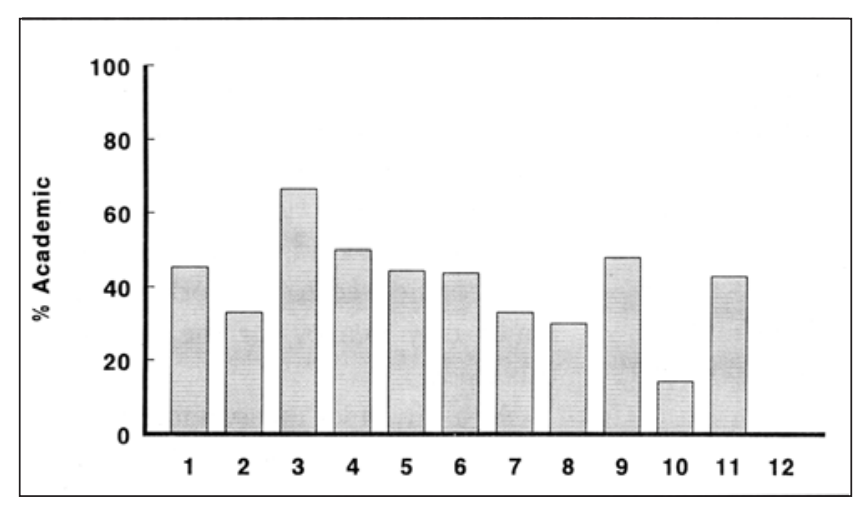

Figure 1) Percentage of trainees in gastroenterology per centre (1-12) affiliated with an academic teaching hospital $(n=170)$

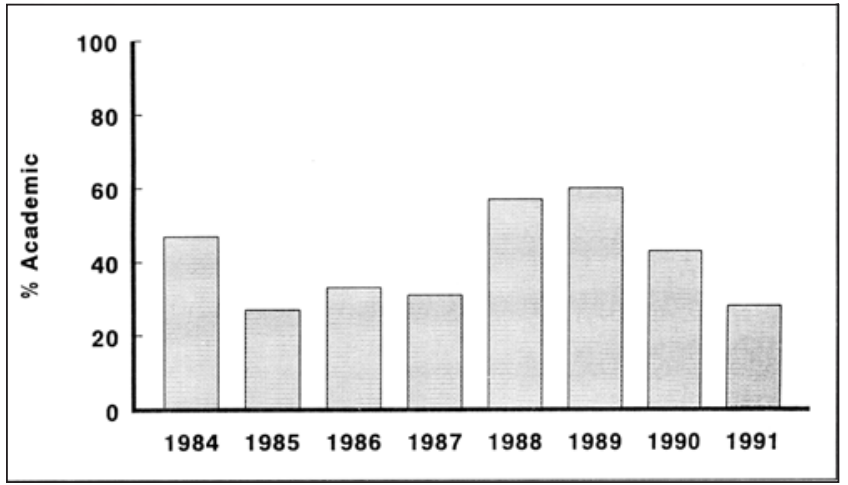

Figure 2) Percentage of trainees entering an academic career according to their initial fellowship year $(n=158)$ 


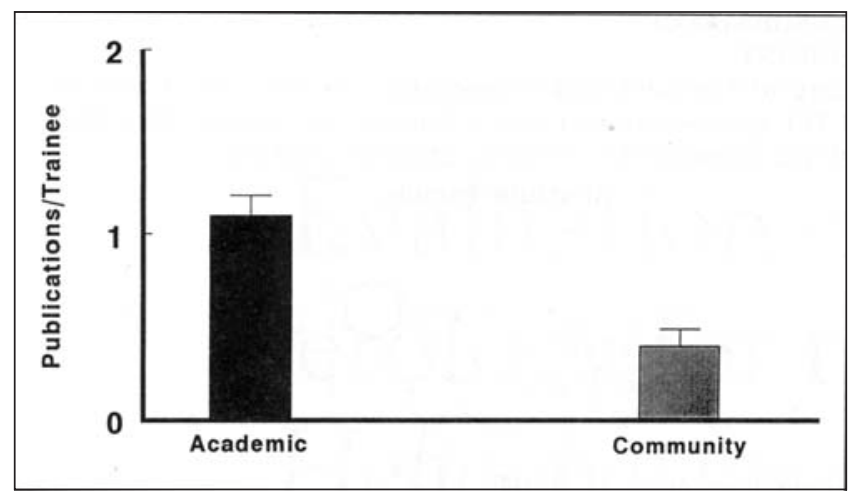

Figure 3) Trainees who pursued an academic career had an average of $1.1 \pm 0.11$ publications during their fellowship period compared with $0.40 \pm 0.09$ publications for trainees entering community-based practice

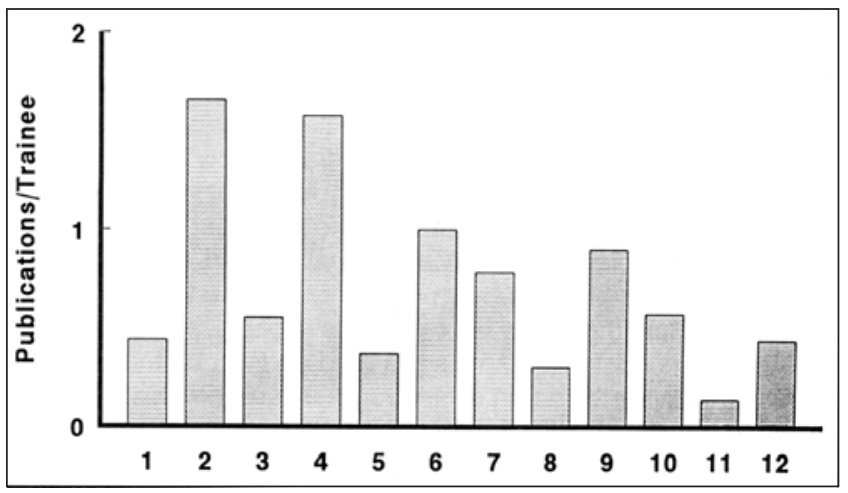

Figure 4) Number of publications per trainee per centre (1-12) over the fellowship period (one year into fellowship to two years postfellowship)
$\mathrm{P}=0.02$, Mann-Whitney test) (Figure 3). The average number of publications per trainee per centre is shown in Figure 4 .

\section{DISCUSSION}

From a simple list of Canadian trainees in gastroenterology we have attempted to look at trends in career choice, academic productivity and geographical distribution. From the career choice perspective, many trainees have chosen to be associated with an academic medical centre. Allowing for the two outlying medical centres, there was a striking similarity to the percentage of trainees entering an academic practice from each individual centre (Figure 1). The percentage seems to be relatively consistent over the study period (Figure 2). There is considerable heterogeneity in the job description, academic expectations and renumeration between Canadian academic centres. The number of trainees who have evolved into clinical investigators with a national or international profile remains small. Furthermore, a Canadian academic job in most centres is more closely related to community practice than in an American academic environment.

We have shown that trainees who publish during their fellowship period are more likely to choose an academic career. This is similar to a recent study in pediatric residents (1). Several $\mathrm{Ca}$ nadian programs have developed a three-year fellowship with more research training. This variability in re- search training may also be reflected in the range of publications per centre and per trainee (Figures 3,4).

Although it is common to relocate to another province, it continues to be uncommon to relocate to another country. Over the study period, $19 \%$ of trainees moved to another country (12\% United States, 7\% other countries). It is likely that the trainees who relocated outside the United States may have originated from those countries and expected to return although that was not clearly established in this study. An anticipated migration of trainees to the United States is not clearly shown in this survey. The uncertainty about health care reform in the United States and the density of gastroenterologists in desirable urban centres may contribute to this observation. Ontario, with five training programs, had a net emigration of trainees that was not offset by the incoming trainees from other provinces.

It was difficult to demonstrate any trend towards trainees moving to smaller cities. This was difficult to assess because many smaller cities have now become suburbs of major Canadian cities. It seems likely that impact analysis requirements and market forces will contribute to the movement of trainees away from the larger cities.

Despite the increasing numbers of female medical graduates, women trainees represented only $13 \%$ of the trainees in this survey. The factors leading to a male predominance in cer- tain specialties such as general surgery may apply to gastroenterology but this remains an area for further study.

Finally, a study of this nature is subject to a number of methodological errors. Some program directors have clearly forwarded names of trainees who may be non-Ministry of Health funded positions, with research, pharmaceutical or foreign sponsors. These trainees may not be representative of a Canadian sample. Some trainees work in more rural settings and yet have a distant affiliation with a medical centre. In this study, these trainees were considered to be in community practice. The methods of searching for publications has some potential for omissions of reports. Publications not listed in Index Medicus were not included although this type of report is usually considered to be of less scientific relevance. The study did not attempt to assess the manpower needs of Canadian gastroenterology in the future (2) and does not suggest that individual centres be evaluated by the above criteria. We hope that these observations will provide a 'snapshot' of our Canadian training programs in gastroenterology which could be used to improve collectively our training programs in the future.

\section{REFERENCES}

1. Ledley FD, Lovejoy FH. Prospects for academically trained pediatricians in academic medicine. Clin Invest Med 1992;15:518-26.

2. Beck IT. History of the first 30 years of the Canadian Association of Gastroenterology. Can J Gastroenterol 1992;6:345-64. 


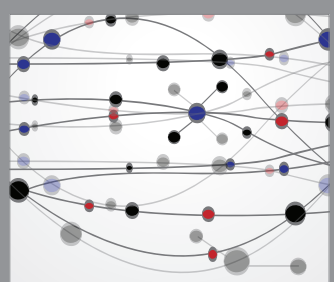

The Scientific World Journal
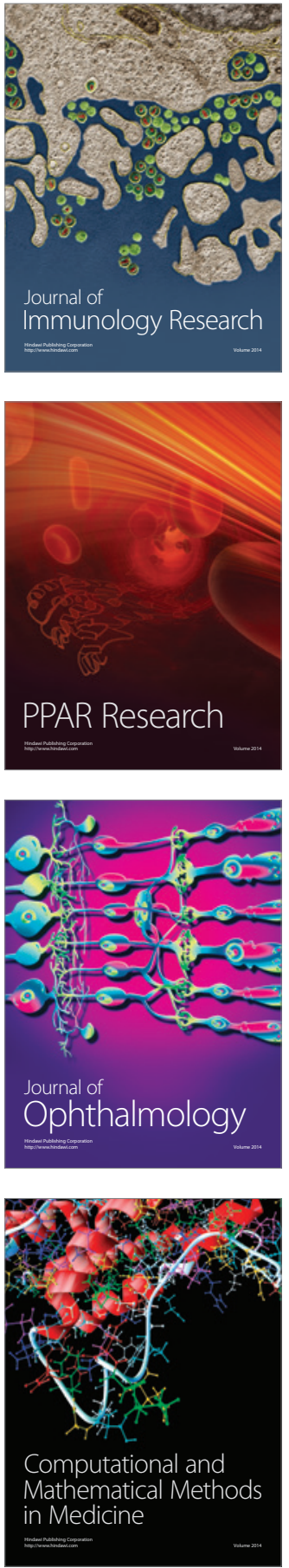

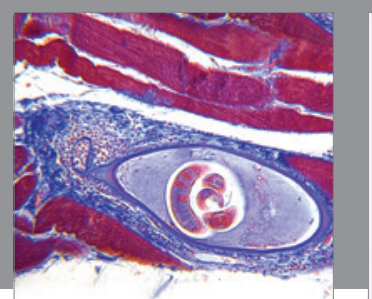

Gastroenterology Research and Practice

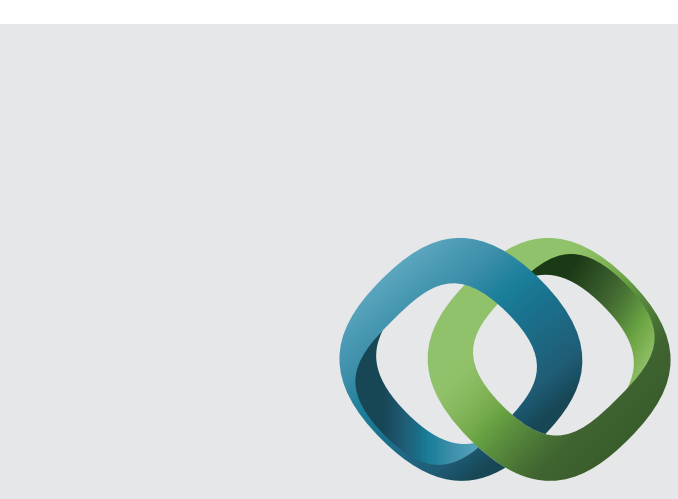

\section{Hindawi}

Submit your manuscripts at

http://www.hindawi.com
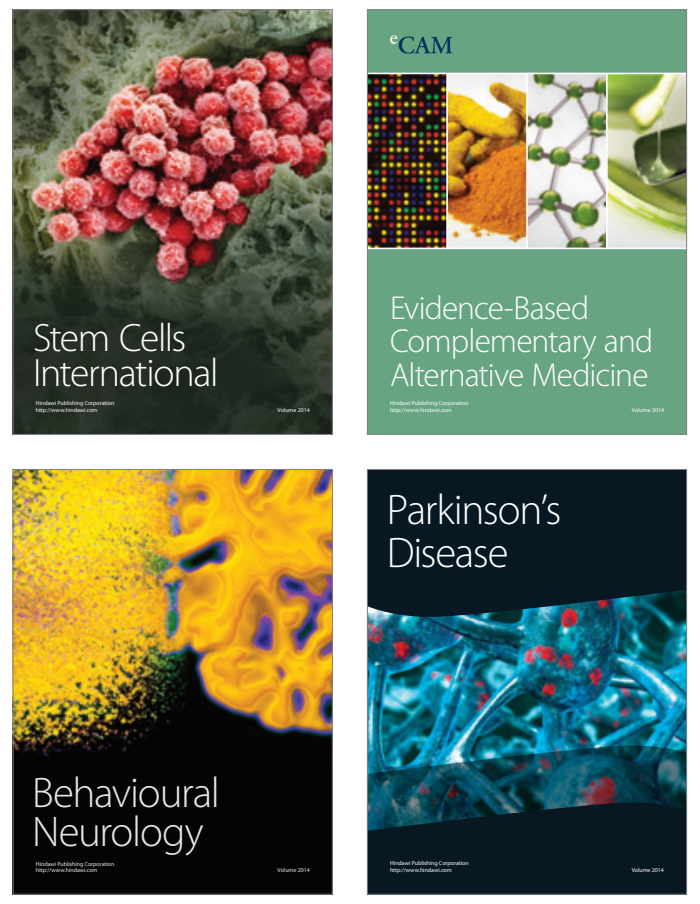
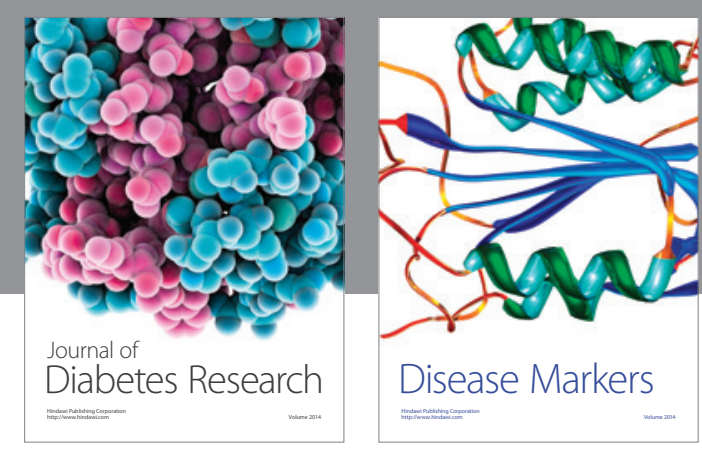

Disease Markers
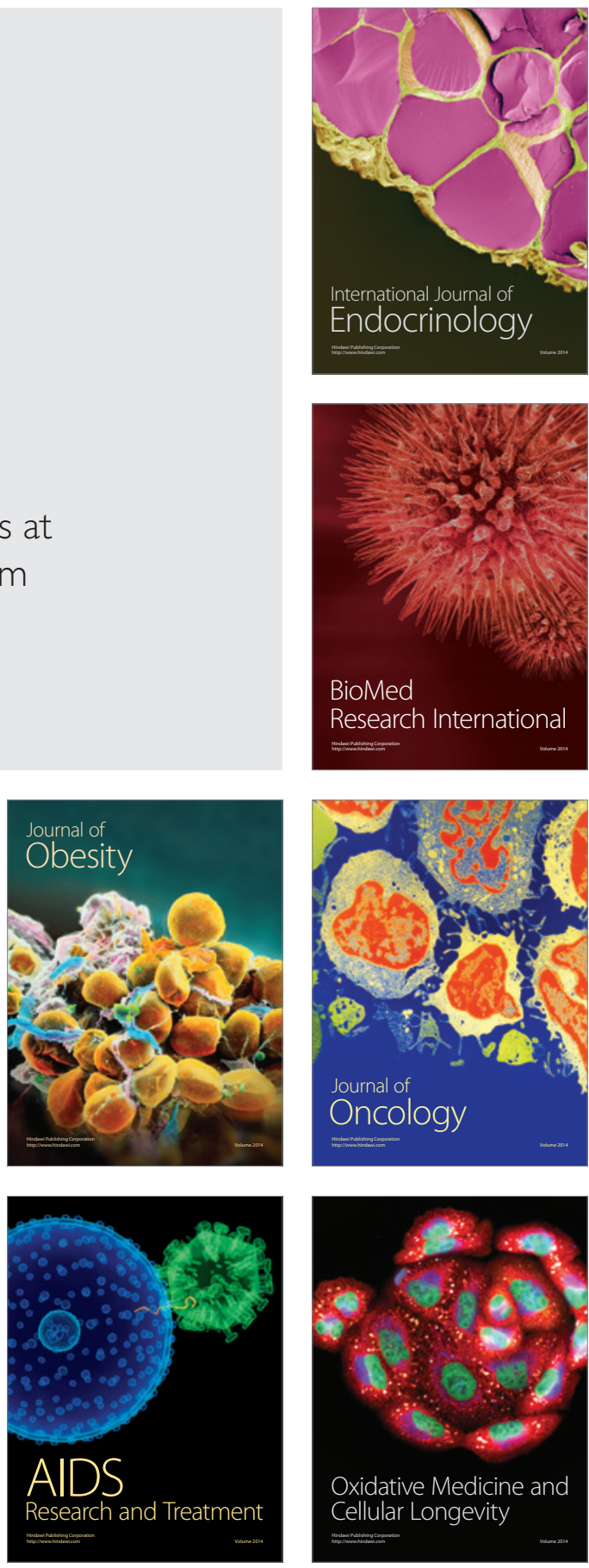